\title{
A proposed modified efficiency for thermosyphon solar heating systems
}

\author{
J.M. Chang ${ }^{\text {a,* }}$, J.S. Leu ${ }^{\text {a }}$, M.C. Shen ${ }^{\text {a }}$, B.J. Huang ${ }^{b}$ \\ a Department of Mechanical Engineering, Far East College, No. 49, Chung-Hwa Road, Hsin-Shih Town, Tainan County 744, Taiwan \\ ${ }^{\mathrm{b}}$ Department of Mechanical Engineering, National Taiwan University, Taipei 106, Taiwan
}

Received 3 January 2003; received in revised form 18 December 2003; accepted 21 January 2004

Communicated by: Associate Editor Claudio Estrada-Gasca

\begin{abstract}
Conventionally, the overall performance rating of a thermosyphon solar water heater considers the thermal performance of the system during the energy-collecting phase and the system cooling loss during the cooling phase. However, this study suggests that the performance rating should also take the heat removal efficiency of the system during the system application phase into consideration. This study modifies the CNS 12557 B7276 test standard and employs a precise, on-line operation to derive the heat removal efficiency of a system. The thermal performance and heat removal efficiency of 12 systems with capacities in the range of $102-446 \mathrm{~L}$ are evaluated. An efficiency coefficient, $\eta_{0}$, is defined, which represents the synthesis of the characteristic thermal performance, $\eta_{\mathrm{s}}^{*}$, and the characteristic heat removal efficiency, $\eta_{\mathrm{R}}^{*}$. The proposed modified efficiency coefficient is given by $\eta_{0}=\eta_{\mathrm{s}}^{*} \times \eta_{\mathrm{R}}^{*}$, and represents the quasioverall performance of a solar heating system. The coefficient provides an effective measure of the amount of energy provided to the user from a system which collects and stores heat from solar radiation. According to prevailing regulations in Taiwan, commercial solar heating products should have a value of $\eta_{\mathrm{s}}^{*}$ in excess of 0.5 in order to attract a government subsidy. The proposed modified efficiency, $\eta_{0}$, is a more practical and representative indication of the actual thermal performance of a system, and accordingly, the present study suggests that the regulations should adopt a value of $\eta_{0} \geqslant 0.41$ as the standard for qualification rather than the current criterion of $\eta_{\mathrm{s}}^{*} \geqslant 0.5$.

(c) 2004 Elsevier Ltd. All rights reserved.
\end{abstract}

\section{Introduction}

It was suggested by Huang and Du (1991) that the overall performance rating of a thermosyphon solar water heater should include the thermal performance of the system during the energy-collecting phase and the system cooling loss during the cooling phase. As discussed by Belessiotis and Mathioulakis (2002), Henden et al. (2002) and Kubler et al. (1988), the thermal performance of a system refers only to its performance during the energy-collecting phase when solar radiation is incident upon the system collectors, i.e. it does not indicate the actual amount of useable energy that a user

\footnotetext{
${ }^{*}$ Corresponding author. Fax: +886-6-5977921.

E-mail address: changjm@ms76.hinet.net (J.M. Chang).
}

will receive from the system. This amount of energy is determined by the mixing effects of the hot water in the storage tank and the cool charge water which flows into the storage tank during the system application phase. Knudsen (2002) investigated the influence of the storage tank volume upon the thermal performance of SDHW systems. His study emphasized the importance of system utilization from the consumer's point of view, and established a relationship between the energy consumed by the user and the volume of the storage tank. However, the heat removal efficiency of the storage tank during the hot water draw-off phase or the system application phase was not considered.

The heat removal efficiency of a system during its application phase is an important consideration when assessing the overall thermal performance of that system since it enables the direct evaluation of the energy which 


\begin{tabular}{|c|c|c|c|}
\hline \multicolumn{4}{|c|}{ Nomenclature } \\
\hline$A_{\mathrm{c}}$ & collector area, $\mathrm{m}^{2}$ & $T_{\mathrm{w}}$ & cool charge water temperature, ${ }^{\circ} \mathrm{C}$ \\
\hline$C_{p}$ & $\begin{array}{l}\text { specific heat with constant pressure condi- } \\
\text { tion, } \mathrm{kJ} /(\mathrm{kg} \mathrm{K})\end{array}$ & $\begin{array}{l}\bar{T}_{\mathrm{w}} \\
t_{95}\end{array}$ & $\begin{array}{l}\text { cool mean charge water temperature, }{ }^{\circ} \mathrm{C} \\
\text { student's } t \text { statistic based on } 95 \% \text { coverage }\end{array}$ \\
\hline$H_{\mathrm{t}}$ & $\begin{array}{l}\text { daily total irradiation upon collector slope, } \\
\mathrm{MJ} /\left(\mathrm{m}^{2} \text { day }\right)\end{array}$ & $U_{\mathrm{s}}$ & $\begin{array}{l}\text { coefficient of overall system loss rate, } \mathrm{MJ} / \\
\left(\mathrm{m}^{2} \mathrm{~K} \text { day }\right)\end{array}$ \\
\hline$M$ & total mass of water in a solar thermosyphon & $V_{\mathrm{t}}$ & volume of a system, $\mathrm{L}$ \\
\hline$\dot{m}_{\mathrm{d}}$ & $\begin{array}{l}\text { system, } \mathrm{kg} \\
\text { discharge flow rate of storage tanks of a } \\
\text { system, } \mathrm{L} / \mathrm{min}\end{array}$ & $\begin{array}{l}\bar{v}_{\mathrm{w}} \\
Z_{x y}\end{array}$ & $\begin{array}{l}\text { daily mean wind speed during testing, } \mathrm{m} / \mathrm{s} \\
\text { correlation coefficient of test data based on } \\
\text { regression analysis, dimensionless }\end{array}$ \\
\hline$Q_{\mathrm{u}}$ & $\begin{array}{l}\text { useful heat which users obtain from a system } \\
\text { in Eq. (4). kJ }\end{array}$ & $\rho_{\mathrm{w}}$ & $\begin{array}{l}\text { density of water, } \mathrm{kg} / \mathrm{m}^{3} \\
\text { modified efficiency of a system, dimension- }\end{array}$ \\
\hline$Q_{\mathrm{t}}$ & total heat which is collected in the storage & & less \\
\hline$R_{\mathrm{i}}$ & $\begin{array}{l}\text { tank of a system by a collector in Eq. (5), } \mathrm{kJ} \\
\text { a distribution factor of solar irradiation, }\end{array}$ & $\eta_{\mathrm{R}}$ & $\begin{array}{l}\text { heat removal efficiency of a system in Eq. } \\
\text { (3), dimensionless }\end{array}$ \\
\hline$t_{\mathrm{f}}$ & $\begin{array}{l}\text { dimensionless } \\
\text { the time required to renovate one storage }\end{array}$ & $\eta_{\mathrm{R}}^{*}$ & $\begin{array}{l}\text { characteristic heat removal efficiency of a } \\
\text { system in Eq. (9), dimensionless }\end{array}$ \\
\hline$T_{\mathrm{a}}$ & $\begin{array}{l}\text { volume by the given flow rate, } \min \\
\text { ambient temperature, }{ }^{\circ} \mathrm{C}\end{array}$ & $\eta_{\mathrm{s}}$ & $\begin{array}{l}\text { daily system efficiency in Eq. (1), dimen- } \\
\text { sionless }\end{array}$ \\
\hline $\begin{array}{l}\bar{T}_{\mathrm{a}} \\
T_{\mathrm{e}}\end{array}$ & $\begin{array}{l}\text { mean ambient temperature, }{ }^{\circ} \mathrm{C} \\
\text { discharge water temperature, }{ }^{\circ} \mathrm{C}\end{array}$ & $\eta_{\mathrm{s}}^{*}$ & $\begin{array}{l}\text { system characteristic efficiency in Eq. (2), } \\
\text { dimensionless }\end{array}$ \\
\hline$T_{\mathrm{i}}$ & initial mean tank temperature, ${ }^{\circ} \mathrm{C}$ & $\alpha_{0}$ & overall solar absorption, dimensionless \\
\hline
\end{tabular}

will be made available to the user. Various forms of draw-off tests exist which relate specifically to storage tanks. These include, but are not restricted to, ANSI/ ASRAE 94.2-1981 (1981), CNS 12557 B7276 (1989), DD ENV 12977-3 (2001) and JIS A 1426 (1995). However, these test standards are inappropriate for thermosyphon solar water heaters with evacuated tube collectors or a number of flat-plate collectors because the volumes of such systems are far higher than the volumes of traditional storage tanks. Moreover, in Taiwan, thermosyphon solar water heaters typically comprise of one or two evacuated tube collectors, each with a volume of between 18 and $48 \mathrm{~L}$. Furthermore, each of these collectors contains between 12 and 48 evacuated tubes plunged into the body of the storage tank, where each individual tube has a volume of between 1.0 and $1.5 \mathrm{~L}$. Therefore, it is difficult to perform a physical heat removal efficiency test on the storage tank in isolation since this would require the removal of the evacuated tubes, which would then leave many holes in the body of the storage tank.

To overcome these difficulties, the current study modifies the CNS test standard (1989) and uses an online operation (Chang, 2002) to conduct a heat removal efficiency test of the complete system including the storage tank and the collectors. An efficiency coefficient, $\eta_{0}$, is defined, which indicates the amount of energy made available to a user by a thermosyphon solar water heating system, and represents the synthesis of the heating system's thermal performance and its heat removal efficiency. In Taiwan, regulations state that purchasers of commercial solar heating systems with a thermal performance, $\eta_{\mathrm{s}}^{*}$, in excess of 0.5 are eligible for a government subsidy. However, the current study suggests that the proposed modified efficiency, $\eta_{0}$, provides a better evaluation of the practical performance of such systems than this thermal performance coefficient, and accordingly, proposes that the subsidy regulations should be re-specified in terms of $\eta_{0}$.

\section{Experimental method}

In order to obtain the modified efficiency of a system, this study first determines its thermal performance during the energy-collection phase and then assesses its heat removal efficiency during the application phase.

The test conditions to be established when determining the thermal performance for a thermosyphon system were specified by Chang et al. (2003) as follows:

1. $R_{\mathrm{i}}$ should lie in the range $0.5 \leqslant R_{\mathrm{i}} \leqslant 1.6$.

2. The daily efficiency test should extend for a period of $9 \mathrm{~h}$, with symmetry about the solar noontime.

3. The total daily solar radiation should be $H_{\mathrm{t}} \geqslant 7 \mathrm{MJ} /$ $\mathrm{m}^{2}$.

4. The daily mean wind speed during the period of the test should be $\bar{v}_{\mathrm{w}} \leqslant 3 \mathrm{~m} / \mathrm{s}$. 
5. The range of operational parameters should be $0 \leqslant\left(T_{\mathrm{i}}-\bar{T}_{\mathrm{a}}\right) / H_{\mathrm{t}} \leqslant 2.5$.

6. A minimum of 10 test points, each of which satisfies the above conditions, must be taken.

Huang and $\mathrm{Du}$ (1991) developed the daily system efficiency model shown below in Eq. (1), where $\alpha_{0}$ represents the daily system efficiency for the case where the initial mean tank temperature $T_{\mathrm{i}}$ equals the mean ambient temperature, $\bar{T}_{\mathrm{a}}$, and $U_{\mathrm{s}}$ is the energy loss coefficient in the energy-collecting phase. The parameters $\alpha_{0}$ and $U_{\mathrm{s}}$ are determined from a linear regression analysis of Eq. (1). As shown in Eq. (2), the test results of $\alpha_{0}$ may be extrapolated to a point with a specified $M / A_{\mathrm{c}}$ value. In his study of 1993 , Huang first defined, and then verified, the thermal performance, $\eta_{\mathrm{s}}^{*}$, as the value of $\alpha_{0}$ corrected at $M / A_{\mathrm{c}}=75 \mathrm{~kg} / \mathrm{m}^{2}$

$\eta_{\mathrm{s}}=\frac{q_{\mathrm{net}}}{H_{\mathrm{t}}}=\alpha_{0}-U_{\mathrm{s}} \frac{T_{\mathrm{i}}-\bar{T}_{\mathrm{a}}}{H_{\mathrm{t}}}$

$\eta_{\mathrm{s}}^{*}=\left.\alpha_{0}\right|_{M / A_{\mathrm{c}}=75}$

In accordance with the guidelines put forward by Chang (2002), the present research modified a CNS test standard (1989) and used an on-line operation to obtain the heat removal efficiency of the system. The configuration of the experimental apparatus adopted in the current study is shown in Fig. 1. A pump is employed to draw off hot water at the outlet of the system at a rate governed by a downstream flow meter. The combined pump and flow meter arrangement facilitates a simple simulation of the typical hot water flow rates that occur in practice when a user draws off water from the system. It is also noted that a second flow meter is installed at the system inlet. For each testing, the flow meters at the inlet and outlet sides of the system enable the charge and discharge flow rates which are the same during the

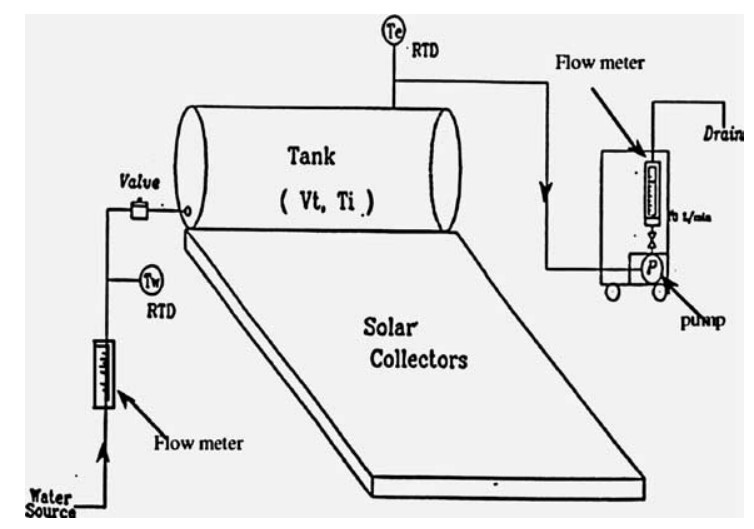

Fig. 1. Configuration of testing system used to evaluate the heat removal efficiency of thermosyphon systems. period of testing for general systems, and which are different during the period of testing for special systems with the regulation of the charge flow. The measurements of the discharge flow temperature, $T_{\mathrm{e}}$, the charge flow temperature, $T_{\mathrm{w}}$, and the initial mean tank temperature, $T_{\mathrm{i}}$ in Fig. 1 are used to calculate the heat removal efficiency of the system.

The heat removal efficiency, $\eta_{\mathrm{R}}$, is shown in Eq. (3), and is defined as the ratio of the useful heat, $Q_{\mathrm{u}}$, to the total heat, $Q_{\mathrm{t}}$, where the useful heat represents the heat obtained from the system by the user, and the total heat indicates the heat which is accumulated by the system collectors from the solar radiation and then stored in the storage tank

$\eta_{\mathrm{R}}=\frac{Q_{\mathrm{u}}}{Q_{\mathrm{t}}}$

where

$Q_{\mathrm{u}}=\int_{0}^{t_{\mathrm{f}}} \dot{m}_{\mathrm{d}} \rho_{\mathrm{w}} C_{p}\left[T_{\mathrm{e}}(t)-T_{\mathrm{w}}(t)\right] \mathrm{d} t$

$Q_{\mathrm{t}}=\rho_{\mathrm{w}} V_{\mathrm{t}} C_{p}\left(T_{\mathrm{i}}-\bar{T}_{\mathrm{w}}\right)$

$t_{\mathrm{f}}=V_{\mathrm{t}} / \dot{m}_{\mathrm{d}}$

$\bar{T}_{\mathrm{w}}=\frac{\int_{0}^{t_{\mathrm{f}}} T_{\mathrm{w}}(t) \mathrm{d} t}{t_{\mathrm{f}}}$

$\eta_{\mathrm{R}}=\frac{\int_{0}^{t_{\mathrm{f}}}\left(T_{\mathrm{e}}(t)-T_{\mathrm{w}}(t)\right) \mathrm{d} t}{\int_{0}^{t_{\mathrm{f}}}\left(T_{\mathrm{i}}-T_{\mathrm{w}}(t)\right) \mathrm{d} t}$

In practice, $Q_{\mathrm{u}}$ is always less than $Q_{\mathrm{t}}$ because the mixing of the cool charge water into a system with the hot water already within the system causes a portion of the total heat to remain within the system when the user draws off water from the tank. Hence, from Eq. (3) it can be seen that the heat removal efficiency, $\eta_{\mathrm{R}}$, must always be less than 1. In Eq. (7), the parameter $t_{\mathrm{f}}$ denotes the time required to renovate one storage volume by the given flow rate during testing of the heat removal efficiency, while $\bar{T}_{\mathrm{w}}$ represents the mean charge water temperature at the inlet of the system during time $t_{\mathrm{f}}$. Eq. (8) gives the heat removal efficiency of the system. It is noted that this equation represents the collation of Eqs. (3)-(7), and that it is expressed in terms of $T_{\mathrm{e}}, T_{\mathrm{w}}$ and $T_{\mathrm{i}}$.

The present study investigates the modified efficiency of the 12 different systems described in Table 1. Of these 12 systems, eight are of the flat-plate collector type with volumes of between 120 and $381 \mathrm{~L}$, while the remainder incorporate one or two evacuated tube collectors and have volumes in the range 102-442 L. To carry out this investigation, CNS12557 B7276 (1989) is modified and an on-line operation of a complete system is used with the following test conditions: 
Table 1

Details of the 12 systems used in the current evaluation of the criterion of modified efficiency

\begin{tabular}{|c|c|c|c|c|}
\hline No. & Systems & Collector types of systems (collector area, $\mathrm{m}^{2}$ ) & Types of storage tank & Volume of storage tank (L) \\
\hline 1 & A & 48 Evacuated tubes (3.64) & Closed, horizontal & 442 \\
\hline 2 & B & 2 Flat plates $(3.8)$ & Closed, horizontal & 294 \\
\hline 3 & $\mathrm{C}$ & 2 Flat plates $(3.71)$ & Closed, horizontal & 287 \\
\hline 4 & $\mathrm{D}$ & 1 Flat plates $(1.89)$ & Closed, horizontal & 120 \\
\hline 5 & $\mathrm{E}$ & 12 Evacuated tubes (1.36) & Closed, horizontal & 102 \\
\hline 6 & $\mathrm{~F}$ & 48 Evacuated tubes (3.64) & Closed, horizontal & 416 \\
\hline 7 & G & 3 Flat plates $(4.28)$ & Open, horizontal & 381 \\
\hline 8 & $\mathrm{H}$ & 3 Flat plates $(5.62)$ & Open, horizontal & 363 \\
\hline 9 & $\mathrm{I}$ & 2 Flat plates $(3.73)$ & Open, horizontal & 306 \\
\hline 10 & $\mathrm{~J}$ & 32 Evacuated tubes (2.42) & $\begin{array}{l}\text { Closed, inclined at } 13^{\circ} \\
\text { to the horizontal }\end{array}$ & 300 \\
\hline 11 & $\mathrm{~K}$ & 2 Flat plates (3.8) & Closed, horizontal & 297 \\
\hline 12 & $\mathrm{~L}$ & 1 Flat plate (1.79) & Closed, horizontal & 147 \\
\hline
\end{tabular}

1. Mean radiation intensity is less than $100 \mathrm{~W} / \mathrm{m}^{2}$.

2. Mean ambient temperature range is $10 \leqslant \bar{T}_{\mathrm{a}} \leqslant 35^{\circ} \mathrm{C}$.

3. Gage pressure of cool water charge flow at the inlet of a system is $P_{\mathrm{i}} \leqslant 0.3 \mathrm{~atm}$.

4. Range of operational parameters is $0 \leqslant\left(T_{\mathrm{i}}-\bar{T}_{\mathrm{w}}\right) /$ $\dot{m}_{\mathrm{d}} \leqslant 6.0$.

5. At least 10 test points that satisfy the above testing conditions are taken.

Regarding the fourth condition above, the empirical model of the heat removal efficiency, $\eta_{\mathrm{R}}$, is in the form of the logarithmic curve $\eta_{\mathrm{R}}=a \ln \left(\left(T_{\mathrm{i}}-\bar{T}_{\mathrm{w}}\right) / \dot{m}_{\mathrm{d}}\right)+b$ established by Chang (2002). It is found that the value of $\eta_{\mathrm{R}}$ remains constant other than within the interval of $1.0 \leqslant\left(T_{\mathrm{i}}-\bar{T}_{\mathrm{w}}\right) / \dot{m}_{\mathrm{d}} \leqslant 3.0$, and that $\eta_{\mathrm{R}}$ maintains a virtually constant value as the value of $\left(T_{\mathrm{i}}-\bar{T}_{\mathrm{w}}\right) / \dot{m}_{\mathrm{d}}$ varies from 3.0 to 6.0. Hence, the characteristic heat removal efficiency, $\eta_{R}^{*}$, shown in Eq. (9) below, is defined as the value of $\eta_{\mathrm{R}}$ at $\left(T_{\mathrm{i}}-\bar{T}_{\mathrm{w}}\right) / \dot{m}_{\mathrm{d}}=2.0$, i.e. the mean value in the range of $1.0 \leqslant\left(T_{\mathrm{i}}-\bar{T}_{\mathrm{w}}\right) / \dot{m}_{\mathrm{d}} \leqslant 3.0$

$\eta_{\mathrm{R}}^{*}=\left.\eta_{\mathrm{R}}\right|_{\left(T_{\mathrm{i}}-\bar{T}_{\mathrm{w}}\right) / \dot{m}_{\mathrm{d}}=2.0}$

The heat removal efficiency of each thermosyphon system in Table 1 is determined via the following procedure: (1) determine the initial mean tank temperature, $T_{\mathrm{i}}$ with the mixing of thermal stratification in the storage tank of a system, (2) establish a specific discharge flow rate of hot water in the range of $5-15 \mathrm{~L} / \mathrm{min}$, (3) use a PC-based data acquisition system to collect data relating to the charge flow temperature, $T_{\mathrm{w}}$, and the discharge flow temperature, $T_{\mathrm{e}}$, once a minute during the testing period, (4) use Eq. (8) to calculate the heat removal efficiency, $\eta_{\mathrm{R}}$, as one system volume is discharged in a time interval of $t_{\mathrm{f}}$, (5) repeat steps 1-4 with different discharge flow rates, $\dot{m}_{\mathrm{d}}$, and temperature differences, $T_{\mathrm{i}}-T_{\mathrm{w}}$, until a minimum of 10 experimental results for the heat removal efficiency have been obtained in order to construct an empirical model of the heat removal efficiency, and (6) find characteristic heat removal efficiency, $\eta_{\mathrm{R}}^{*}$, with the empirical model of heat removal efficiency,

$\eta_{\mathrm{R}}=a \ln \left(\left(T_{\mathrm{i}}-\bar{T}_{\mathrm{w}}\right) / \dot{m}_{\mathrm{d}}\right)+b, \quad$ at $\eta_{\mathrm{R}}^{*}=\left.\eta_{\mathrm{R}}\right|_{\left(T_{\mathrm{i}}-\bar{T}_{\mathrm{w}}\right) / \dot{m}_{\mathrm{d}}=2.0}$

The resistance temperature detectors (RTD), precision spectral pyranometers, wind speed meters and flow meters used for collecting data in the current test configuration were well calibrated by their respective standard instruments. Table 3 presents the results of an uncertainty analysis of the various experimental measurements involved in determining the modified efficiency. The calculation of the uncertainty of a single parameter is based on the root-sum-square model proposed by Hayward (1977) with a 95\% confidence interval. Meanwhile, the calculation of the combined uncertainty of several independent parameters is based on the root-sum-square model presented by Abernethy et al. (1983) with a $95 \%$ confidence interval $\left(t_{95}=2.0\right)$, a relative sensitivity factor of 1.0 for $\eta_{\mathrm{s}}^{*}$, and a relative sensitivity factor of 1.4 for $\eta_{\mathrm{R}}^{*}$. The uncertainty of the modified efficiency established in the present study is $11.8 \%$, where the uncertainty of the thermal performance is $5.4 \%$ and the uncertainty of the characteristic heat removal efficiency is $6.4 \%$.

\section{Experimental results and verification}

In determining the modified efficiency of the thermosyphon solar heating system, this study first tested its thermal performance and its heat removal efficiency.

\subsection{Test results and verification of thermal performance}

The thermal performance of 12 systems was tested in this study. The daily efficiencies of systems A, B, C and $\mathrm{D}$ are shown in Figs. 2-5, respectively. Applying linear 


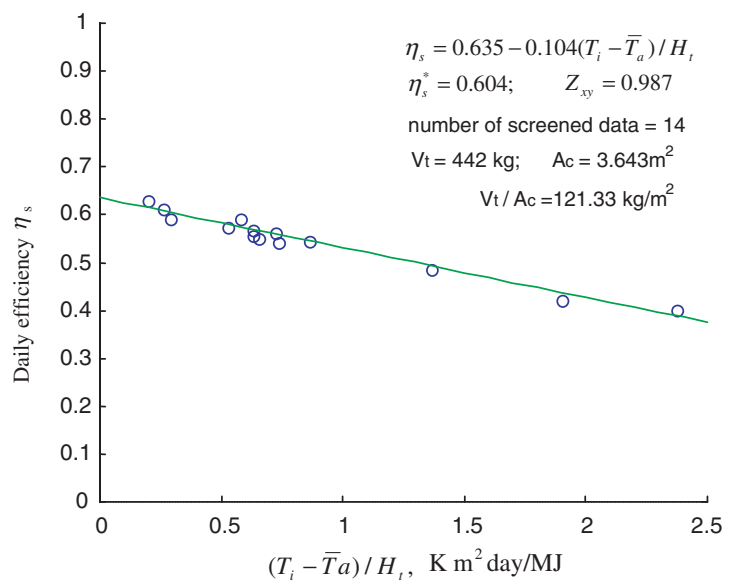

Fig. 2. Daily efficiency test results of system A with $\eta_{\mathrm{s}}^{*}=0.604$.

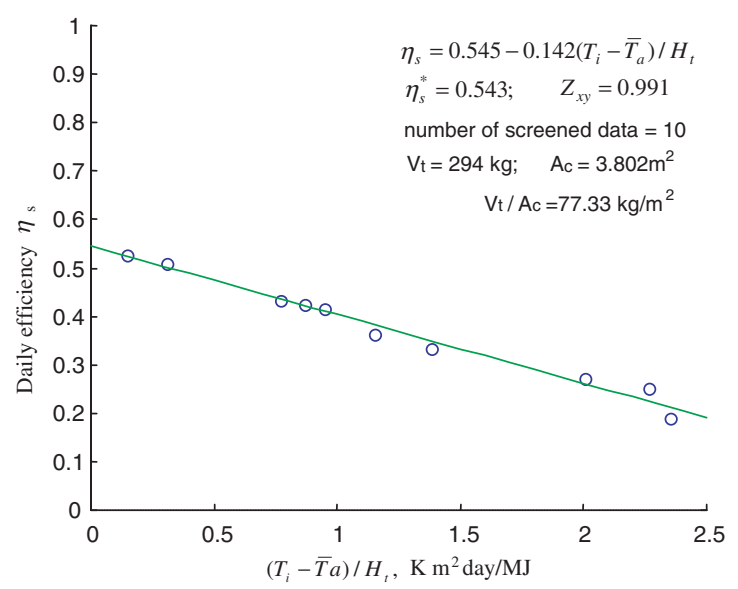

Fig. 3. Daily efficiency test results of system B with $\eta_{\mathrm{s}}^{*}=0.543$.

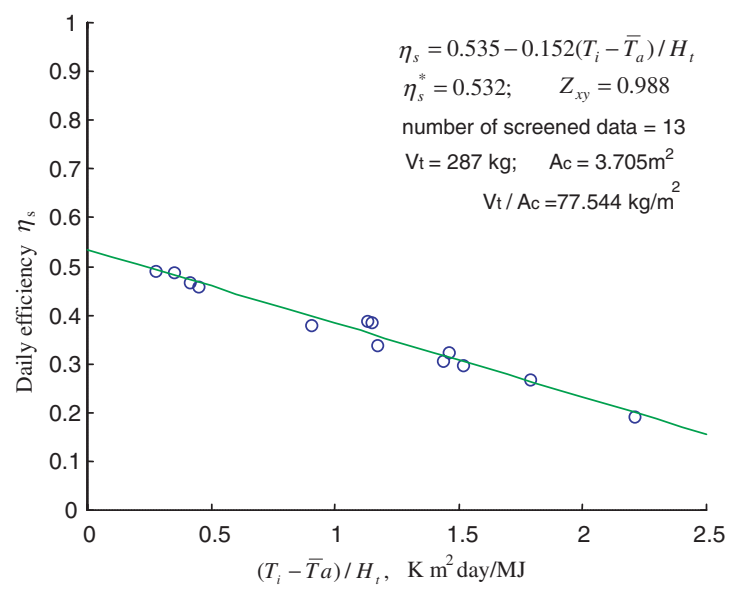

Fig. 4. Daily efficiency test results of system $\mathrm{C}$ with $\eta_{\mathrm{s}}^{*}=0.532$.

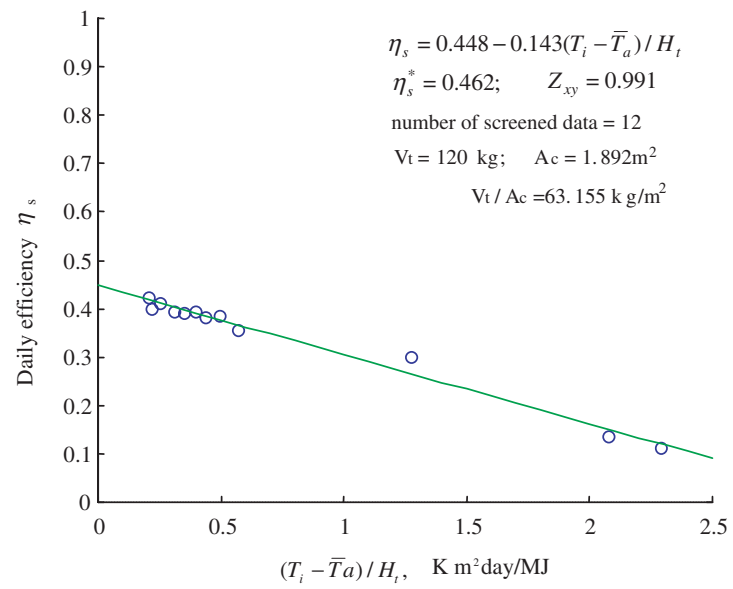

Fig. 5. Daily efficiency test results of system D with $\eta_{\mathrm{s}}^{*}=0.462$.

regression analysis to these results yields values which enable the calculation of the thermal performance of these systems. The results for $\eta_{\mathrm{s}}^{*}$ presented in Table 2 for systems A, B, C and D indicate thermal performances of $0.604,0.543,0.532$ and 0.462 respectively. The overall mean value of the system characteristic efficiency of the 12 systems is found to be 0.54 . It is noted that the mean value of the system characteristic efficiency for the eight systems with flat-plate collectors is 0.51 and the mean value of the four systems with evacuated tube collectors is 0.59 . Furthermore, Table 2 indicates that the data correlation for the thermal performance of the 12 systems is very high, i.e. in the range of $0.945-0.993$. The present results suggest that the criterion of thermal performance, $\eta_{\mathrm{s}}^{*}$, used currently in subsidy regulations should adopt a value of $\eta_{\mathrm{s}}^{*} \geqslant 0.51$ rather than the present value of $\eta_{\mathrm{s}}^{*} \geqslant 0.5$, which was determined from a CNS test standard (1989) 14 years ago. Note that the $2 \%$ increase in the thermal performance of the commercial systems indicates an improvement in the quality of such systems since that time.

\subsection{Test results and verification of heat removal efficiency}

On-line operation of each of the 12 flat-plate collector or evacuated tube collector systems presented in Table 1 was performed in order to evaluate the heat removal efficiency of each system. During the testing stage, discharge rates at the outlet of the storage tank were established in the range of $5-15 \mathrm{~L} / \mathrm{min}$ to reflect the flow rates which typically occur in practical thermosyphon solar heating system applications. The test results for the heat removal efficiency of systems A, B, C and D are presented in Figs. 6-9, respectively. The results reveal that the heat removal efficiency of the system decreases as the discharge flow rate increases. This observation may be explained by considering the 
Table 2

Details of the thermal performance, characteristic heat removal efficiency and modified efficiency of the 12 systems

\begin{tabular}{|c|c|c|c|c|c|c|}
\hline \multirow[t]{2}{*}{ No. } & \multirow[t]{2}{*}{ Systems } & \multicolumn{2}{|c|}{ System characteristic efficiency } & \multicolumn{2}{|c|}{ Characteristic heat removal efficiency } & \multirow{2}{*}{$\begin{array}{l}\text { Modified efficiency } \\
\eta_{0}=\eta_{\mathrm{s}}^{*} \times \eta_{\mathrm{R}}^{*}\end{array}$} \\
\hline & & $\eta_{\mathrm{s}}^{*}$ & $\begin{array}{l}\text { Correlation coefficient } \\
Z_{x y}\end{array}$ & $\eta_{\mathrm{R}}^{*}$ & $\begin{array}{l}\text { Correlation coefficient } \\
Z_{x y}\end{array}$ & \\
\hline 1 & A & 0.604 & 0.987 & 0.833 & 0.952 & 0.503 \\
\hline 2 & $\mathrm{~B}$ & 0.543 & 0.991 & 0.8 & 0.928 & 0.434 \\
\hline 3 & $\mathrm{C}$ & 0.532 & 0.988 & 0.846 & 0.939 & 0.45 \\
\hline 4 & $\mathrm{D}$ & 0.462 & 0.991 & 0.723 & 0.906 & 0.334 \\
\hline 5 & $\mathrm{E}$ & 0.525 & 0.983 & 0.689 & 0.901 & 0.362 \\
\hline 6 & $\mathrm{~F}$ & 0.623 & 0.993 & 0.811 & 0.913 & 0.505 \\
\hline 7 & $\mathrm{G}$ & 0.502 & 0.976 & 0.885 & 0.926 & 0.444 \\
\hline 8 & $\mathrm{H}$ & 0.513 & 0.963 & 0.869 & 0.904 & 0.446 \\
\hline 9 & I & 0.504 & 0.976 & 0.784 & 0.901 & 0.395 \\
\hline 10 & $\mathrm{~J}$ & 0.601 & 0.983 & 0.841 & 0.889 & 0.505 \\
\hline 11 & $\mathrm{~K}$ & 0.514 & 0.945 & 0.8 & 0.928 & 0.411 \\
\hline 12 & $\mathrm{~L}$ & 0.533 & 0.99 & 0.748 & 0.967 & 0.399 \\
\hline \multirow{2}{*}{\multicolumn{2}{|c|}{$\begin{array}{l}\text { Range } \\
\text { Mean value }\end{array}$}} & $0.462-0.623$ & $0.945-0.993$ & $0.689-0.885$ & $0.889-0.967$ & $0.334-0.505$ \\
\hline & & $\begin{array}{l}\mathbf{0 . 5 4} \text {, including } \\
\text { flat plate: } \mathbf{0 . 5 1} \text {; } \\
\text { evacuated tube: } \\
\mathbf{0 . 5 9}\end{array}$ & 0.98 & 0.80 & 0.921 & $\begin{array}{l}\mathbf{0 . 4 3} \text {, including flat } \\
\text { plate: } \mathbf{0 . 4 1} \text {; evacu- } \\
\text { ated tube: } \mathbf{0 . 4 7}\end{array}$ \\
\hline
\end{tabular}

Note that the results indicate a mean value of 0.41 as the criterion of modified efficiency, $\eta_{0} \geqslant 0.41$.

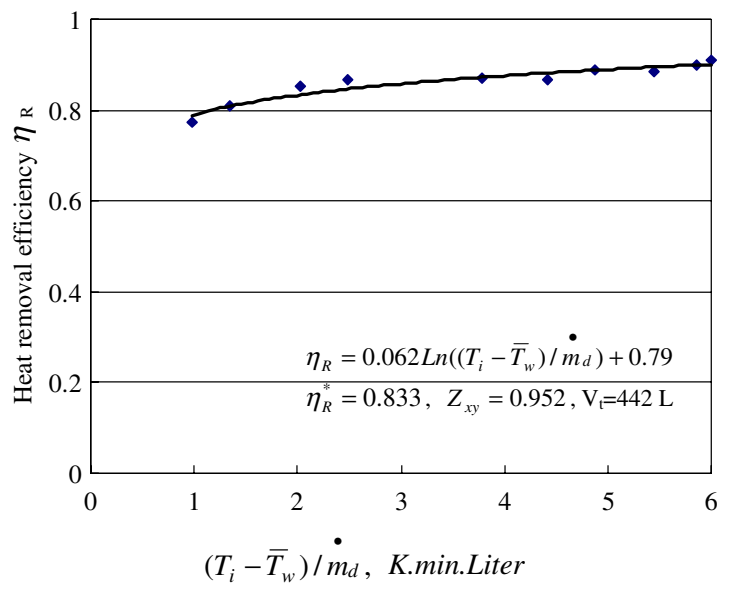

Fig. 6. Heat removal efficiency for system A with $\eta_{\mathrm{R}}^{*}=0.833$.

thermal stratification within the storage tank which is formed by the cool charge water flowing into the system and the hot water which is already present in the system. During testing, this stratification is easily destroyed when the discharge flow rate is sufficiently high to induce strong water jets to enter the storage tank (Shah et al., 2001). Furthermore, it is noted that the heat removal efficiency increases with an increasing temperature difference, $T_{\mathrm{i}}-\bar{T}_{\mathrm{w}}$. This trend is the result of a strong thermal stratification effect for higher values of the temperature difference. Accordingly, Chang (2002) de-

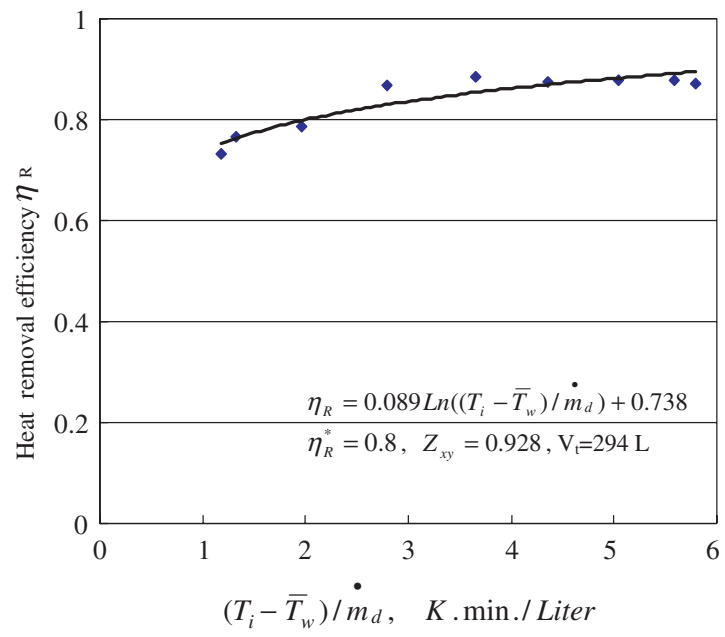

Fig. 7. Heat removal efficiency for system $\mathrm{B}$ with $\eta_{\mathrm{R}}^{*}=0.8$.

fined a new integral variable, $\left(T_{\mathrm{i}}-\bar{T}_{\mathrm{w}}\right) / \dot{m}_{\mathrm{d}}$, as an operational parameter to construct an empirical model of the heat removal efficiency, which had the form of a logarithmic curve.

From Table 2, it can be seen that the mean value of the heat removal efficiency for the 12 systems is 0.8 , and that the data correlation coefficient is in the high range of $0.889-0.967$. Therefore, the current experimental results suggest that the criterion of heat removal efficiency, $\eta_{\mathrm{R}}^{*}$, should adopt a value of $\eta_{\mathrm{R}}^{*} \geqslant 0.8$. 


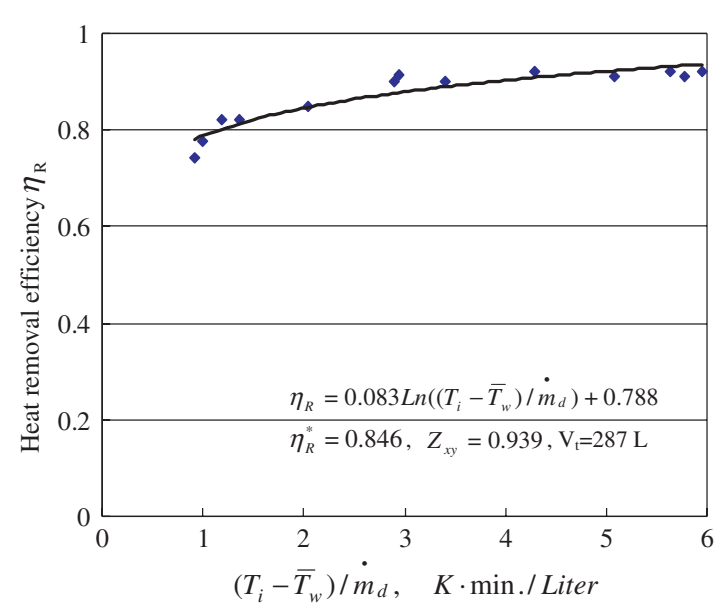

Fig. 8. Heat removal efficiency for system $\mathrm{C}$ with $\eta_{\mathrm{R}}^{*}=0.846$.

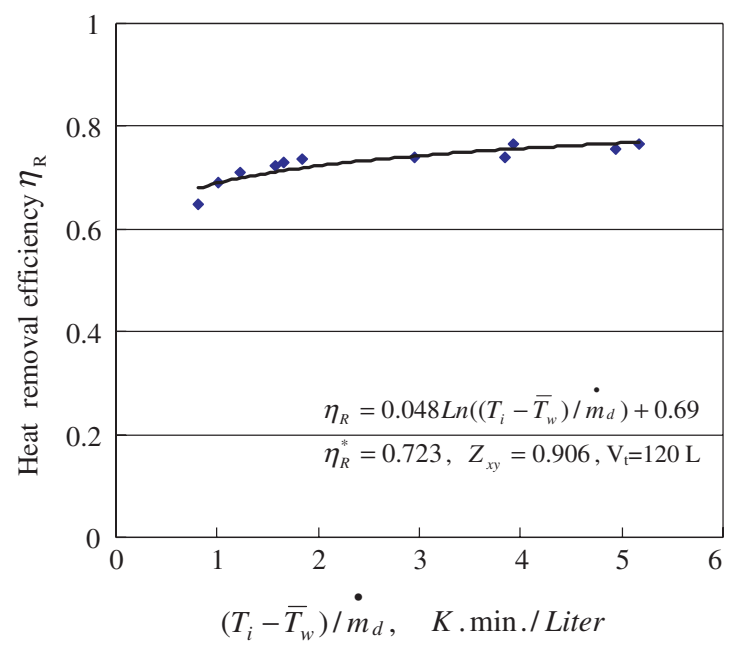

Fig. 9. Heat removal efficiency for system $\mathrm{D}$ with $\eta_{\mathrm{R}}^{*}=0.723$.

\subsection{Development of the criterion of modified efficiency}

The characteristic thermal performance, $\eta_{\mathrm{s}}^{*}$, and the characteristic heat removal efficiency, $\eta_{\mathrm{R}}^{*}$, of each of the 12 systems are presented in Table 2. The modified efficiency, $\eta_{0}$, proposed in the current study combines the thermal performance and the heat removal efficiency in the form $\eta_{0}=\eta_{\mathrm{s}}^{*} \times \eta_{\mathrm{R}}^{*}$. The modified efficiency, $\eta_{0}$, represents the quasi-overall performance of a system during its energy-collecting phase and system application phase. With a daily total radiation, $H_{\mathrm{t}}$, upon the collector slope of a system, $\eta_{0}$ is an effective means of evaluating the amount of energy provided to a user from the solar radiation.

The modified efficiency of each of the 12 systems is shown in Table 2. The mean value of the modified effi- ciency is shown to be 0.43 , where the mean value of modified efficiency for the eight systems with flat-plate collectors is 0.41 and that of the four systems with evacuated tube collectors is 0.47 . Therefore, the experimental results suggest that the criterion of modified efficiency, $\eta_{0}$, should be $\eta_{0} \geqslant 0.41$. Furthermore, the mean value of 0.43 for the modified efficiency of the 12 systems indicates that users of domestic thermosyphon solar heating systems receive an average of $43 \%$ of the total solar energy, $H_{\mathrm{t}}$, incident on the collectors of the system.

\section{Discussion}

Heat loss in the storage tank of a system occurs if the value of the heat removal efficiency, $\eta_{\mathrm{R}}$, is less than 1.0. There are two principal origins of heat loss during the testing process: (1) the thermal stratification of the cool charge water and the hot water in the system is destroyed by the cool charge water flow due to a poor storage tank design, and (2) the thickness of the storage tank insulation is insufficient to prevent heat from leaking out of the system. These two situations are also responsible for system cooling loss during the cooling stage of the application phase. Hence, the modified efficiency, $\eta_{0}$, which is based on the characteristic heat removal efficiency, $\eta_{\mathrm{R}}^{*}$, for the application phase and the cooling phase, and on the system characteristic efficiency, $\eta_{\mathrm{s}}^{*}$, for the energy-collecting phase represents the quasi-overall performance of a system in a practical implementation. Moreover, the criterion of modified efficiency, i.e. $\eta_{0} \geqslant 0.41$, which is established in the present study is credible because all of the experimental data relating to the testing of thermal performance and heat removal efficiency have been verified with a high data correlation coefficient in the range of 0.889-0.993 (as shown in Table 2) and with a reasonable uncertainty of $11.8 \%$ (as shown in Table 3).

Table 4 presents a comparison of the testing methods used to evaluate the thermal performance and heat removal efficiency in the current study with those adopted previously by other test standards. Regarding the testing of the thermal performance, it is noted that the current test results are virtually the same as those obtained from ISO 9459-2 (1995) under a test error of 9\%. This similarity is explained by the fact that the testing conditions employed in both cases are the same other than the test time period and the wind speed limit. In the current study, the test time period was modified from the test time period specified in ISO 9459-2 (1995), i.e. from 6:00 $\mathrm{AM}$ to 6:00 PM. It was found that the test results for the thermal performance are unchanged if the coefficient of heat loss during the cooling phase (Huang and Du, 1991) does not exceed $2.5 \mathrm{~W} /{ }^{\circ} \mathrm{C}$. If this condition is not achieved, it is determined that the value of thermal 
Table 3

Uncertainty analysis of experimental measurements for modified efficiency

\begin{tabular}{|c|c|c|c|c|c|c|c|}
\hline \multirow[t]{2}{*}{ Parameter } & \multicolumn{3}{|c|}{$\begin{array}{l}\text { Thermal performance } \\
\eta_{\mathrm{s}}^{*}=f\left(\left(T_{\mathrm{i}}-\bar{T}_{\mathrm{a}}\right) / H_{\mathrm{t}}, \bar{v}_{\mathrm{w}}\right)\end{array}$} & \multicolumn{3}{|c|}{$\begin{array}{l}\text { Characteristic heat removal efficiency } \\
\eta_{\mathrm{R}}^{*}=f\left(\left(T_{\mathrm{i}}-\bar{T}_{\mathrm{w}}\right) / \dot{m}_{\mathrm{d}}\right)\end{array}$} & \multirow{2}{*}{$\begin{array}{l}\text { Modified } \\
\text { efficiency } \\
\eta_{0}=\eta_{\mathrm{s}}^{*} \times \eta_{\mathrm{R}}^{*}\end{array}$} \\
\hline & $\begin{array}{l}\text { Accuracy } \\
\text { error }(\%)\end{array}$ & $\begin{array}{l}\text { Precision } \\
\text { error }(\%)\end{array}$ & $\begin{array}{l}\text { Uncertainty } \\
(\%)\end{array}$ & $\begin{array}{l}\text { Accuracy } \\
\text { error }(\%)\end{array}$ & $\begin{array}{l}\text { Precision } \\
\text { error }(\%)\end{array}$ & $\begin{array}{l}\text { Uncer- } \\
\text { tainty }(\%)\end{array}$ & \\
\hline Temperature difference & \pm 0.2 & \pm 4.0 & \pm 4.0 & \pm 0.2 & \pm 4.0 & \pm 4.0 & \\
\hline $\begin{array}{l}\text { Solar irradiation } \\
\text { intensity }\end{array}$ & \pm 1.5 & \pm 2.5 & \pm 2.9 & & & & \\
\hline Wind speed & \pm 2.0 & \pm 1.0 & \pm 2.2 & & & & \\
\hline Flow rate & & & & \pm 1.0 & \pm 2.0 & \pm 2.2 & \\
\hline Total uncertainty & $\pm \mathbf{5 . 4} \%$ & & & $\pm 6.4 \%$ & & & $\pm \mathbf{1 1 . 8} \%$ \\
\hline
\end{tabular}

Note that the uncertainty of the modified efficiency established in the present study is $11.8 \%$, where the uncertainty of the thermal performance is $5.4 \%$ and the uncertainty of the characteristic heat removal efficiency is $6.4 \%$.

Notes: 1. The calculation of uncertainty of one parameter is based on the familiar root-sum-square model (Hayward, 1977) with the $95 \%$ confidence interval. 2 . The calculation of uncertainty of several independent parameters into a result is based on the familiar rootsum-square model (Abernethy et al., 1983) with the $95 \%$ confidence interval $\left(t_{95}=2.0\right.$ ), a relative sensitivity factor of 1.0 calculated for $\eta_{\mathrm{s}}^{*}$ and a relative sensitivity factor of 1.4 calculated for $\eta_{\mathrm{R}}^{*}$.

Table 4

Comparison of current test method with other test standards

\begin{tabular}{|c|c|c|c|c|c|c|c|}
\hline \multirow[t]{2}{*}{$\begin{array}{l}\text { Test } \\
\text { conditions }\end{array}$} & \multicolumn{2}{|c|}{$\begin{array}{l}\text { The test method for thermal } \\
\text { performance }\end{array}$} & \multicolumn{5}{|c|}{ The test method for heat removal efficiency } \\
\hline & ISO 9459-2 & $\begin{array}{l}\text { Testing of } \\
\text { this study }\end{array}$ & $\begin{array}{l}\text { ANSI/AS- } \\
\text { RAE 94.2- } \\
1981\end{array}$ & CNS B7276 & $\begin{array}{l}\text { DD ENV } \\
12977-3\end{array}$ & JIS A 1426 & $\begin{array}{l}\text { Testing of } \\
\text { this study }\end{array}$ \\
\hline $\begin{array}{l}\text { Total daily } \\
\text { solar } \\
\text { irradiation }\end{array}$ & $\begin{array}{l}H_{\mathrm{t}} \geqslant 8 \mathrm{MJ} / \\
\left(\mathrm{m}^{2} \text { day }\right)\end{array}$ & $\begin{array}{l}H_{\mathrm{t}} \geqslant 7 \mathrm{MJ} / \\
\left(\mathrm{m}^{2} \text { day }\right)\end{array}$ & \multirow[t]{8}{*}{$\begin{array}{l}\text { Test method } \\
\text { for storage } \\
\text { tanks only }\end{array}$} & \multirow[t]{8}{*}{$\begin{array}{l}\text { Test method } \\
\text { for storage } \\
\text { tanks only }\end{array}$} & \multirow[t]{8}{*}{$\begin{array}{l}\text { Test method } \\
\text { for storage } \\
\text { tanks only }\end{array}$} & \multirow[t]{8}{*}{$\begin{array}{l}\text { Test method } \\
\text { for storage } \\
\text { tanks only }\end{array}$} & \multirow{8}{*}{$\begin{array}{l}\text { Test method } \\
\text { with an on- } \\
\text { line system } \\
\text { operation for } \\
\text { a whole sys- } \\
\text { tem includ- } \\
\text { ing storage } \\
\text { tanks and } \\
\text { collectors }\end{array}$} \\
\hline $\begin{array}{l}\text { Range of } \\
\text { operational } \\
\text { parameters }\end{array}$ & $\begin{array}{l}-0.2 \leqslant\left(T_{\mathrm{i}}-\bar{T}_{\mathrm{a}}\right) / \\
H_{\mathrm{t}} \leqslant 2.5\end{array}$ & $\begin{array}{l}0 \leqslant\left(T_{\mathrm{i}}-\bar{T}_{\mathrm{a}}\right) / \\
H_{\mathrm{t}} \leqslant 2.5\end{array}$ & & & & & \\
\hline Test points & Six points at least & $\begin{array}{l}\text { Ten points at } \\
\text { least }\end{array}$ & & & & & \\
\hline \multirow{3}{*}{$\begin{array}{c}\text { Test time } \\
\text { period }\end{array}$} & $12 \mathrm{~h}$ from & $9 \mathrm{~h}$ from & & & & & \\
\hline & 6:00 AM to & 7:30 AM to & & & & & \\
\hline & 6:00 PM & 4:30 PM & & & & & \\
\hline $\begin{array}{l}\text { Daily mean } \\
\text { wind speed }\end{array}$ & $\bar{v}_{\mathrm{w}} \geqslant 3 \mathrm{~m} / \mathrm{s}$ & $\bar{v}_{\mathrm{w}} \leqslant 3 \mathrm{~m} / \mathrm{s}$ & & & & & \\
\hline $\begin{array}{l}\text { A distribution } \\
\text { factor of solar } \\
\text { irradiation, } R_{\mathrm{i}}\end{array}$ & No & $0.5 \leqslant R_{\mathrm{i}} \leqslant 1.6$ & & & & & \\
\hline
\end{tabular}

Regarding the testing of the thermal performance, it is noted that the current test results are virtually the same as those obtained from ISO 9459-2 (1995) under a test error of $9 \%$.

performance derived from ISO $9459-2$ (1995) is $9 \%$ lower than the result obtained from the current study. The ISO 9459-2 (1995) standard specified a wind speed of $\bar{v}_{\mathrm{w}} \geqslant 3 \mathrm{~m} / \mathrm{s}$. However, this is inappropriate for the prevailing climate conditions in Taiwan, where wind speeds rarely exceed $3 \mathrm{~m} / \mathrm{s}$. In practice, the test time period and wind speed conditions specified in ISO 94592 should be modified to reflect the local climate within which the thermosyphon solar heating system is situ- ated. Failing that, testing of the thermal performance could be performed from early morning to night, which conforms to the test time period specified in ISO 9459-2 (1995), and over an extended period of several months in order to maximize the possibility of collecting data, which conforms to the wind speed condition of $\bar{v}_{\mathrm{w}} \geqslant 3$ $\mathrm{m} / \mathrm{s}$. Regarding the testing of heat removal efficiency, no test methods exist to deal with a system which incorporates evacuated tube collectors other than the test 
method using an on-line system operation presented in this study. Moreover, the testing procedure of heat removal efficiency in the study is different from those of other test methods because the empirical model created in this study results in the difference of operational parameters and the on-line system operation presented in this study results in the difference of required test time.

\section{Conclusions}

The present study has evaluated the thermal performance and heat removal efficiency of 12 different types of thermosyphon solar water heating systems. A modified efficiency coefficient, $\eta_{0}$, has been defined in the form of $\eta_{0}=\eta_{\mathrm{s}}^{*} \times \eta_{\mathrm{R}}^{*}$, and represents the practical quasioverall performance of a system over the application phase, the cooling phase and the energy-collecting phase. The present results have suggested a criterion of modified efficiency of $\eta_{0} \geqslant 0.41$. Current regulations in Taiwan stipulate that commercial thermosyphon solar heating systems should demonstrate a thermal efficiency, $\eta_{\mathrm{s}}^{*}$, in excess of 0.5 in order to qualify for government subsidy. However, based upon the experimental results presented in this study, it is the current authors' belief that the proposed modified efficiency, $\eta_{0}$, provides a more representative measure of the performance of such systems. Accordingly, it is proposed that the criterion of modified efficiency, $\eta_{0} \geqslant 0.41$, should be adopted as the standard for qualification in this regulation.

\section{Acknowledgements}

The authors wish to acknowledge the support provided to this study by the Energy Commission, Ministry of Economic Affairs in Taiwan under contract nos. NEC 89-A, NEC 90-A and NEC 91-A.

\section{References}

Abernethy, R.B., Benedict, R.P., Dowdell, R.B., 1983. ASME measurement uncertainty. ASME paper 83-WA/FM-3.
ANSI/ASRAE 94.2-1981, 1981. Methods of testing-thermal storage devices with electrical input and thermal out based on thermal performance. Approved by ASHRAE Standards Committee.

Belessiotis, V., Mathioulakis, E., 2002. Analytical approach of thermosyphon solar domestic hot water system performance. Solar Energy 72 (4), 307-315.

Chang, J.M., 2002. Empirical model of heat removal efficiency for the storage tanks of solar heating systems. In: Proceedings of The Fourth ISES-Europe Solar Congress, Solar Thermal Systems Session, Bologna, Italy.

Chang, J.M., Shen, M.C., Huang, B.J, 2003. A criterion study of solar irradiation patterns for the performance testing of thermosyphon solar water heaters. Solar Energy 73 (4), 287292.

CNS Standard B7276, No. 12557, 1989. Method of test for thermal performance of solar storage tanks. Central Bureau of Standard, Ministry of Economic Affairs, Taiwan.

DD ENV 12977-3, 2001. Thermal solar systems and components-custom built systems. Part 3: Performance characterization of stores for solar heating systems. British Standards Publishing Limited (BSPL).

Hayward, A.T.J., 1977. Repeatability and Accuracy. Mechanical Engineering Publication, Ltd., London.

Henden, L., Rekstad, J., Meir, M., 2002. Thermal performance of combined solar systems with different collector efficiencies. Solar Energy 72 (4), 299-305.

Huang, B.J., 1993. Performance rating method of thermosyphon solar water heaters. Solar Energy 59 (5), 435-440.

Huang, B.J., Du, S.C., 1991. A performance test method of solar thermosyphon systems. Transactions of the ASME Solar Energy Engineering 113, 172-179.

ISO 9459-2, 1995. Solar heating-domestic water heating systems. Part 2: Outdoor test method for system performance characterization and yearly performance prediction of solar-only systems, first edition.

JIS A 1426, 1995. Test method of thermal performance for solar storage tanks. Japanese Standards Association.

Knudsen, S., 2002. Consumers' influence on the thermal performance of small SDHW systems - theoretical investigations. Solar Energy 73 (1), 33-42.

Kubler, R., Ernst, M., Fisch, N., 1988. Short term test for solar domestic hot water systems - experimental results and long term performance prediction. In: Advances in Solar Energy, vol. 1. Pergamon Press, Oxford, UK, pp. 732-736.

Shah, L.J., Andersen, E., Furbo, S., Knudsen, S., Heller, A.J., 2001. Entrance effects in solar hot water stores. In: Proceedings of ISES 2001 Solar World Congress, Direct Solar Systems And Application Session, Adelaide, South Australia. 